\title{
Role of annealing temperature on the properties of SrO nanoparticles by precipitation method
}

\author{
R. Suresh a, ${ }^{*}$, T. Indira Priyadharshini a, K. Thirumal Valavan a, M. Justin Paul a
}

a Department of Physics, Sri Ramakrishna Mission Vidyalaya College of Arts and Science, Coimbatore-641020, Tamil Nadu, India. *Corresponding author Email: rsdphy@gmail.com

DOI: https://doi.org/10.34256/nnxt2013

Received: 15-11-2020; Accepted: 18-11-2020; Published: 19-11-2020

Abstract: Strontia nanoparticles are successfully prepared by chemical precipitation method. The SrO nanoparticles are characterized by XRD, UV-DRS and I-V analysis. X-ray diffraction peaks reveal the single-phase polycrystalline tetragonal structure with preferential orientation along $\left(\begin{array}{lll}2 & 0 & 2\end{array}\right)$ direction. Influence of annealing temperature strongly induce the growth of peak which indicates the increased intensity of (202) peak. The heat treatment strongly distresses the growth of triplet peaks (002), (101) and (110) whereas the same augment the growth of (202) and (310). Strontium oxide nanoparticles would allow more light for absorption in UV region due to its rough surface whereas the same would allow moderate light absorption in visible region due to its high packing density. The expansion and contraction of $\mathrm{Sr}-\mathrm{O}$ bonds leads to a high crystalline nature with its purity at $322 \mathrm{~nm}$. It is proposed that strain and surface defects in SrO nanocrystal take place due to different absorption edge.

Keywords: SrO, Tetragonal structure, XRD, DRS

\section{Introduction}

Metal oxides play a very important role in many areas of chemistry, physical and materials science. The metal oxides are attracting meticulous attention from researchers due to their easy mode of formation and multifunctional behavior. The research in the area of nanostructured metal oxides; gradually gather popularity for their remarkable properties in electronic, magnetic, optical, thermal and mechanical domains [1]. Among these metal oxides, Strontium is an alkaline earth metal and its oxide Strontia ( $\mathrm{SrO}$ ) is a strongly basic oxide. Strontium Oxide ( $\mathrm{SrO}$ ) is well known industrially important compound and component in clay, special glass and ceramic products. Nanocrystalline $\mathrm{SrO}$ is a superimposed particle morphology with size that shows excellent high thermal stability and good optical properties [2]. In addition, $\mathrm{SrO}$ is electronically conductive and has been used in solar cell, fuel cell, gas sensors, and cathode materials in the solid oxide form as an oxygen generation system. Strontium oxide nanoparticles are extensively used in the cathode ray tube industry, in which they are employed in the form of aluminum alloy to shield humans from X-ray emissions from the traditional color television [3-6]. Nanosized SrO materials with welldefined particle morphology and size shows an excellent optical, thermal, high oxidation resistance, high mechanical, electric, chemical inertness and magnetic properties. Due to its unique properties, it has received more attention both in basic and applied research for fabricating the devices [7]. SrO nanopowder have a hierarchical morphology which may help to design the devices for gas sensors, solar cells, doped semiconductors, dye-sensitized solar cells, transistors, electrodes for lithium ion batteries, catalyst supports and as well as super capacitors [8-12]. In the present work, an attempt has been made to prepare Strontium oxide nanoparticles and investigate their structural, optical and electrical properties.

\section{Materials and methods}

All reagents used in the synthesis were analytical grade and used without further purification. Strontium oxide nanoparticles were prepared through homogeneous precipitation method. In a typical synthesis, $0.5 \mathrm{M}$ of strontium chloride was dissolved in $50 \mathrm{ml}$ of deionized water under ultrasonicating and allowed to stir for complete dissolution of the compound at $60^{\circ} \mathrm{C} .10 \mathrm{ml}$ aqueous solution of potassium and sodium hydroxide (1M) was added drop-wise separately to the above solution to maintain $\mathrm{pH}$ and the reaction was allowed to stir for $5 \mathrm{~h}$ at $60^{\circ} \mathrm{C}$. At the end of the reaction, the pale white colored slurry 
was formed. The obtained precipitates were washed several times with deionized water and absolute ethanol separately to remove the soluble impurities and dried at $120^{\circ} \mathrm{C}$ for $1 \mathrm{~h}$. The resultant precipitates were further treated with an appropriate calcination temperature $\left(400^{\circ} \mathrm{C}\right.$ for $\left.3 \mathrm{~h}\right)$ to obtain better quality Strontium oxide nanocrystallites. The color of the samples has been changed from pale white to milky white and dark white during the heat treatment. The color change of the Strontium oxide (pale white for stoichiometric powder to dark white for nonstoichiometric one) also can be justified by existence of strontium vacancy and/or interstitial oxygen [13]. The detailed synthesis process was explained as follows.

$\mathrm{SrCl}_{2} .6 \mathrm{H}_{2} \mathrm{O}+2 \mathrm{KOH} \stackrel{60^{\circ} \mathrm{C}}{\longrightarrow} \mathrm{Sr}(\mathrm{OH})_{2}+2 \mathrm{KCl}+6 \mathrm{H}_{2} \mathrm{O}$

$\mathrm{Sr}(\mathrm{OH})_{2} \stackrel{400^{\circ} \mathrm{C}}{\longrightarrow} \mathrm{SrO}+\mathrm{H}_{2} \mathrm{O}$

\section{Results and discussion}

\subsection{Structural characterization}

The crystal phase and purity of the assynthesized SrO nano powders were identified using the powder X-ray diffraction (XRD) measurement. Fig. 1a shows the XRD pattern of strontium oxide nanoparticles from $\mathrm{KoH}$ precipitant. It indicates the presence of single-phase tetragonal structure with preferred orientation along (202) reflection and (also match well) have a good agreement with the standard data of strontium oxide (JCPDS card No. 01-1113). Nine sharp and strong Bragg peaks are observed at the angles of (their maxima centered at) $2 \theta=14.30$, $19.69,24.36,25.34,28.29,31.84,35.22,36.39$ and $39.38^{\circ}$, which corresponds to crystal the planes of (101), (112), (200), (202), (114), (213), (222), (310) and (312), respectively [14]. The diffraction peaks in the XRD pattern are very narrow and sharp, which represents the samples thus prepared are good crystalline materials (indicates the good crystallinity of the SrO samples). Influence of annealing temperature strongly induce the growth of peak which indicates the increased intensity of (202) peak. The new peak (112) introduced at $2 \theta=17.01$ during heat treatment, which enhance the growth of (202) and (310) whereas the same anguish the growth of (101) and (114). Fig. 1b shows the XRD pattern of strontium oxide nanoparticles prepared from $\mathrm{NaOH}$ precipitant. These XRD pattern confirms the polycrystalline nature with preferred orientation along (202) reflection i.e. normal to the plane of particle surface. Influence of annealing temperature strongly induce the growth of peak which indicates the increased intensity of (202) peak. The heat treatment strongly distresses the growth of triplet peaks (002), (101) and (110) whereas the same augment the growth of (202) and (310). The preferred orientation was changed from (101) to (202) during annealing which indicates the prepared samples are highly crystalline nature. The crystallite size of the SrO samples is calculated using Debye-Scherrer formula and it is found to be in the range 23.9-102 $\mathrm{nm}$. The increase in crystallite size is may be owing to change in nucleation process caused by induced stress due to the presence of heat treatment which leads to coalescence of islands to form bigger crystallites [15].

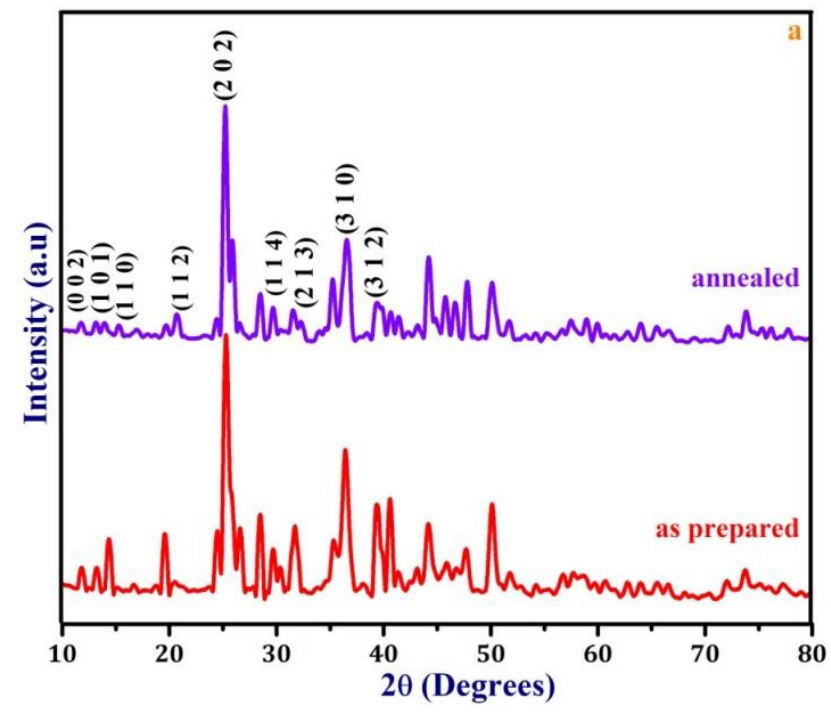

Figure 1a XRD patterns of Strontium oxide nanoparticles prepared from $\mathrm{KoH}$

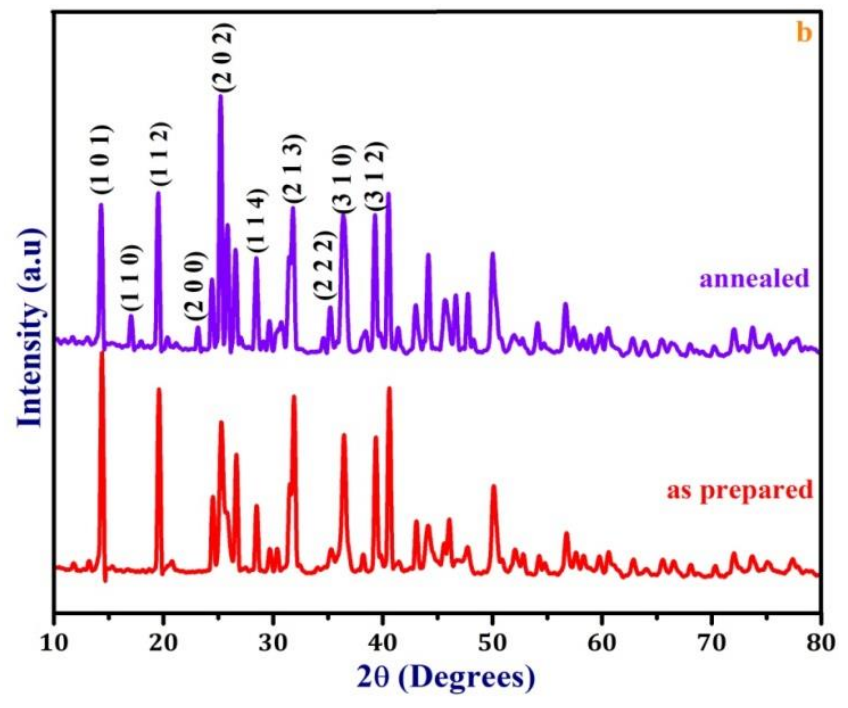

Figure 1b XRD patterns of Strontium oxide nanoparticles prepared from $\mathrm{NaOH}$ 
Table 1 Structural properties of SrO nanoparticles prepared from $\mathrm{KoH}$ and $\mathrm{NaOH}$

\begin{tabular}{|c|c|c|c|c|c|c|c|c|}
\hline \multirow{2}{*}{$\begin{array}{c}\text { Sample } \\
\text { name }\end{array}$} & \multirow{2}{*}{$\begin{array}{c}2 \\
\text { Theta }\end{array}$} & \multirow{2}{*}{ FWHM } & \multirow{2}{*}{ hkl } & \multirow{2}{*}{$\begin{array}{l}\text { Crystallite } \\
\text { Size (nm) }\end{array}$} & \multirow{2}{*}{$\begin{array}{c}\text { Dislocation } \\
\text { Density } \\
10^{14} \\
\text { (lines } / \mathbf{m}^{2} \text { ) }\end{array}$} & \multirow{2}{*}{$\begin{array}{c}\text { Strain } \\
10^{-2} \\
\operatorname{lin}^{-2} \mathbf{m}^{-4}\end{array}$} & \multicolumn{2}{|c|}{$\begin{array}{c}\text { Lattice } \\
\text { Constant ( } \AA \text { ) }\end{array}$} \\
\hline & & & & & & & $\mathbf{a}$ & C \\
\hline $\begin{array}{c}\mathrm{KoH} \\
\text { asprepare } \\
\mathrm{d}\end{array}$ & $\begin{array}{l}11.71 \\
13.04 \\
14.17 \\
20.61 \\
25.15 \\
29.76 \\
31.60 \\
36.51 \\
39.46\end{array}$ & $\begin{array}{l}0.1004 \\
0.1338 \\
0.0836 \\
0.1338 \\
0.2676 \\
0.1673 \\
0.1673 \\
0.3346 \\
0.1338\end{array}$ & $\begin{array}{l}002 \\
101 \\
110 \\
112 \\
202 \\
114 \\
213 \\
310 \\
312\end{array}$ & $\begin{array}{l}79.5 \\
59.7 \\
95.8 \\
60.3 \\
30.4 \\
49.1 \\
49.3 \\
25.1 \\
63.1\end{array}$ & $\begin{array}{l}1.58 \\
2.80 \\
1.09 \\
2.74 \\
10.8 \\
4.14 \\
4.10 \\
15.9 \\
2.51\end{array}$ & $\begin{array}{l}0.1853 \\
0.1825 \\
0.1916 \\
0.1776 \\
0.1844 \\
0.1885 \\
0.1891 \\
0.1815 \\
0.1950\end{array}$ & $\begin{array}{l}3.621 \\
3.582 \\
3.546 \\
3.575 \\
3.562 \\
3.601 \\
3.587 \\
3.593 \\
3.543\end{array}$ & $\begin{array}{l}6.556 \\
6.563 \\
6.542 \\
6.578 \\
6.593 \\
6.581 \\
6.597 \\
6.580 \\
6.587\end{array}$ \\
\hline $\begin{array}{c}\mathrm{KoH} \\
\text { annealed }\end{array}$ & $\begin{array}{l}13.21 \\
15.31 \\
20.77 \\
25.20 \\
28.47 \\
31.58 \\
36.64 \\
39.81\end{array}$ & $\begin{array}{l}0.3346 \\
0.2676 \\
0.2007 \\
0.1338 \\
0.2676 \\
0.2676 \\
0.1673 \\
0.2007\end{array}$ & $\begin{array}{l}101 \\
110 \\
112 \\
202 \\
114 \\
213 \\
310 \\
312\end{array}$ & $\begin{array}{l}23.9 \\
29.9 \\
40.2 \\
60.8 \\
30.6 \\
30.8 \\
50.2 \\
42.1\end{array}$ & $\begin{array}{c}17.49 \\
11.13 \\
6.17 \\
2.70 \\
10.65 \\
10.50 \\
3.99 \\
5.64\end{array}$ & $\begin{array}{l}0.1495 \\
0.1653 \\
0.1808 \\
0.1895 \\
0.1815 \\
0.1834 \\
0.1911 \\
0.1902\end{array}$ & $\begin{array}{l}3.565 \\
3.562 \\
3.508 \\
3.568 \\
3.549 \\
3.573 \\
3.561 \\
3.559\end{array}$ & $\begin{array}{l}6.593 \\
6.594 \\
6.584 \\
6.580 \\
6.573 \\
6.558 \\
6.589 \\
6.592\end{array}$ \\
\hline $\begin{array}{c}\mathrm{NaOH} \\
\text { asprepare } \\
\mathrm{d}\end{array}$ & $\begin{array}{l}14.30 \\
19.69 \\
24.36 \\
25.34 \\
28.29 \\
31.84 \\
35.22 \\
36.39 \\
39.38\end{array}$ & $\begin{array}{l}0.1338 \\
0.1338 \\
0.1171 \\
0.2676 \\
0.1338 \\
0.1338 \\
0.3346 \\
0.2007 \\
0.0836\end{array}$ & $\begin{array}{l}101 \\
112 \\
200 \\
202 \\
114 \\
213 \\
222 \\
310 \\
312\end{array}$ & $\begin{array}{c}59.8 \\
60.2 \\
69.4 \\
30.4 \\
61.2 \\
61.7 \\
24.9 \\
41.6 \\
100.9\end{array}$ & $\begin{array}{c}2.79 \\
2.75 \\
2.07 \\
10.79 \\
2.66 \\
2.62 \\
16.10 \\
5.75 \\
0.98\end{array}$ & $\begin{array}{l}0.1831 \\
0.1586 \\
0.1916 \\
0.1786 \\
0.1920 \\
0.1921 \\
0.1819 \\
0.1896 \\
0.1957\end{array}$ & $\begin{array}{l}3.542 \\
3.540 \\
3.552 \\
3.579 \\
3.549 \\
3.573 \\
3.564 \\
3.568 \\
3.554\end{array}$ & $\begin{array}{l}6.578 \\
6.574 \\
6.569 \\
6.596 \\
6.587 \\
6.584 \\
6.594 \\
6.572 \\
6.592\end{array}$ \\
\hline $\begin{array}{c}\mathrm{NaoH} \\
\text { annealed }\end{array}$ & $\begin{array}{l}14.25 \\
17.01 \\
19.46 \\
23.21 \\
25.16 \\
28.42 \\
31.74 \\
35.18 \\
36.47 \\
39.34\end{array}$ & $\begin{array}{l}0.1673 \\
0.1338 \\
0.1338 \\
0.1338 \\
0.1004 \\
0.2342 \\
0.1506 \\
0.1338 \\
0.3346 \\
0.0836\end{array}$ & $\begin{array}{l}101 \\
110 \\
112 \\
200 \\
202 \\
114 \\
213 \\
222 \\
310 \\
312\end{array}$ & $\begin{array}{c}47.8 \\
60.2 \\
60.6 \\
60.9 \\
81.1 \\
35.1 \\
54.8 \\
62.3 \\
25.2 \\
100.9\end{array}$ & $\begin{array}{l}4.36 \\
2.77 \\
2.75 \\
2.72 \\
1.52 \\
8.16 \\
3.32 \\
2.58 \\
15.9 \\
0.98\end{array}$ & $\begin{array}{l}0.1781 \\
0.1851 \\
0.1872 \\
0.1882 \\
0.1926 \\
0.1839 \\
0.1914 \\
0.1925 \\
0.1831 \\
0.1955\end{array}$ & $\begin{array}{l}3.543 \\
3.559 \\
3.560 \\
3.563 \\
3.579 \\
3.538 \\
3.555 \\
3.568 \\
3.572 \\
3.564\end{array}$ & $\begin{array}{l}6.585 \\
6.587 \\
6.584 \\
6.573 \\
6.593 \\
6.597 \\
6.576 \\
6.564 \\
6.596 \\
6.582\end{array}$ \\
\hline
\end{tabular}


The calculated structural parameters are listed in Table 1. From the structural characterization, samples prepared from $\mathrm{NaOH}$ precipitant indicate superior crystalline behavior than the samples prepared from $\mathrm{KoH}$ precipitant owing to its high catalytic activity during particle formation.

\subsection{Optical characterization}

Absorbance spectra of the SrO nanoparticles prepared with $\mathrm{KoH}$ and $\mathrm{NaOH}$ are shown in Fig. 2. It also shows a sharp and strong absorption edge in the wavelength 238 and $322 \mathrm{~nm}$ in the UV region for the samples prepared from $\mathrm{NaOH}$ precipitant whereas the same obtained at $288 \mathrm{~nm}$ for the samples prepared from $\mathrm{KoH}$ precipitant. The prominent broad exciton absorption band was observed at 238 and $288 \mathrm{~nm}$ which support the formation of mono- dispersible colloidal particle due to quantum confinement effect [13]. The presence of broad absorption peak at 322 $\mathrm{nm}$ supports the surface morphology which further tends to controls the size and purity of the particle. Strontium oxide nanoparticles would allow more light for absorption in UV region due to its rough surface whereas the same would allow moderate light absorption in visible region due to its high packing density. The expansion and contraction of $\mathrm{Sr}-\mathrm{O}$ bonds leads to a high crystalline nature with its purity at 322 $\mathrm{nm}$. It is proposed that strain and surface defects in SrO nanocrystal take place due to different absorption edge. The annealing temperature plays a crucial role in accelerating the growth mechanism with well defined nanostructure with desired morphology and phase purity. Diffuse reflectance spectra of Strontium oxide nanoparticles prepared from $\mathrm{KoH}$ and $\mathrm{NaOH}$ are shown in Fig. 3.

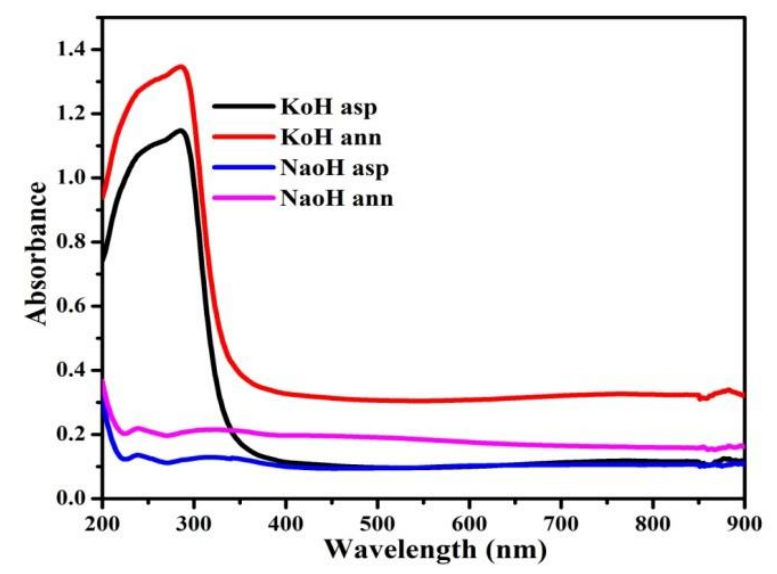

Figure 2 UV-ViS absorbance spectra of Strontium oxide nanoparticles.

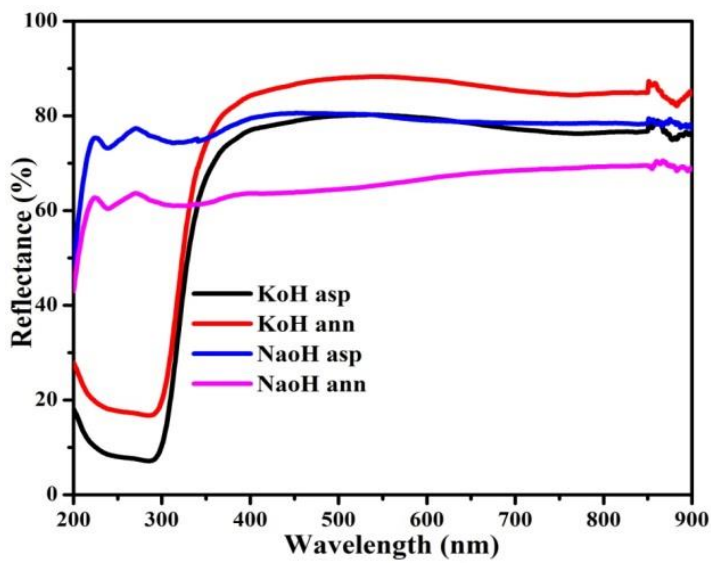

Figure 3 DRS of Strontium oxide nanoparticles.

It increases up to a certain wavelength in UV region, then decreases exponentially and finally becomes constant in the visible region. The calculated refractive index decreases from 3.82 to 3.71 with annealing temperature. The decrease in refractive index with annealing temperature is mainly due the decrease of packing density and crystallite size. The values of the tangents intercepting the energy axis give the values of optical band gap as shown in Fig. 4. The calculated optical band gap is found to be in the range 3.96 to $4.13 \mathrm{eV}$ for indirect allowed transitions. From the optical characterization, samples prepared from $\mathrm{KoH}$ precipitant exhibit peculiar absorbance and reflectance in UV region than the samples prepared from $\mathrm{NaOH}$ precipitant owing to its high optical activity in UV region.

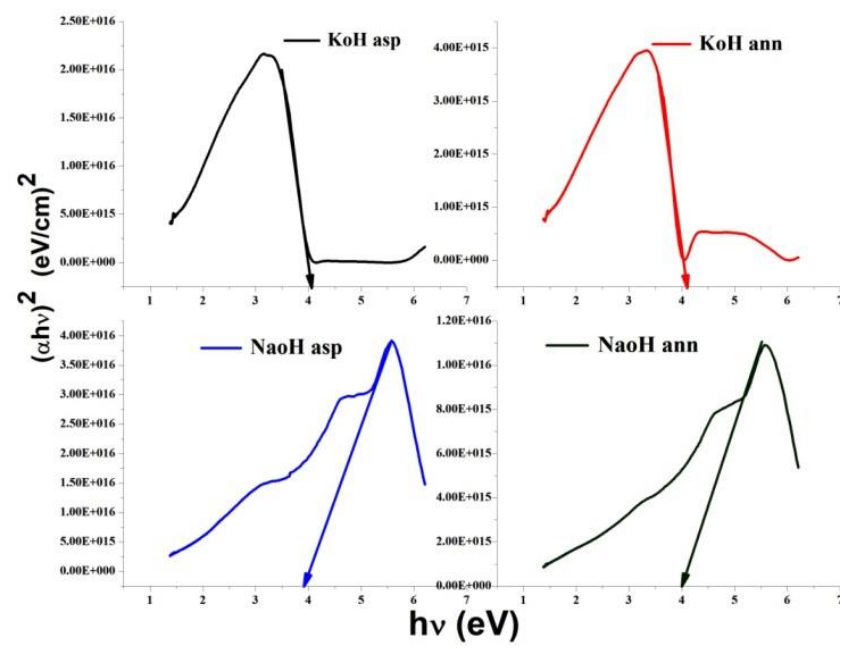

Figure 4 Plot of band gap energy of Strontium oxide nanoparticles.

\subsection{Electrical characterization}

I-V characteristics of the SrO nanoparticles prepared form $\mathrm{KoH}$ and $\mathrm{NaOH}$ precipitants are represented in Fig. 5. It show sharp conductivity decrease with annealing temperature due to the 
presence of un-evaporated precursor solvent and incorporation of $\mathrm{NaOH}$ and $\mathrm{KoH}$ into the host SrO lattice respectively. The calculated conductivity is found to be in the range $4.96 \times 10^{-7}-1.54 \times 10^{-6} \mathrm{~S} / \mathrm{cm}$. From the electrical characterization, samples prepared from $\mathrm{KoH}$ precipitant indicate high electrical conductivity than the samples prepared from $\mathrm{NaOH}$ precipitant owing to low band gap energy.

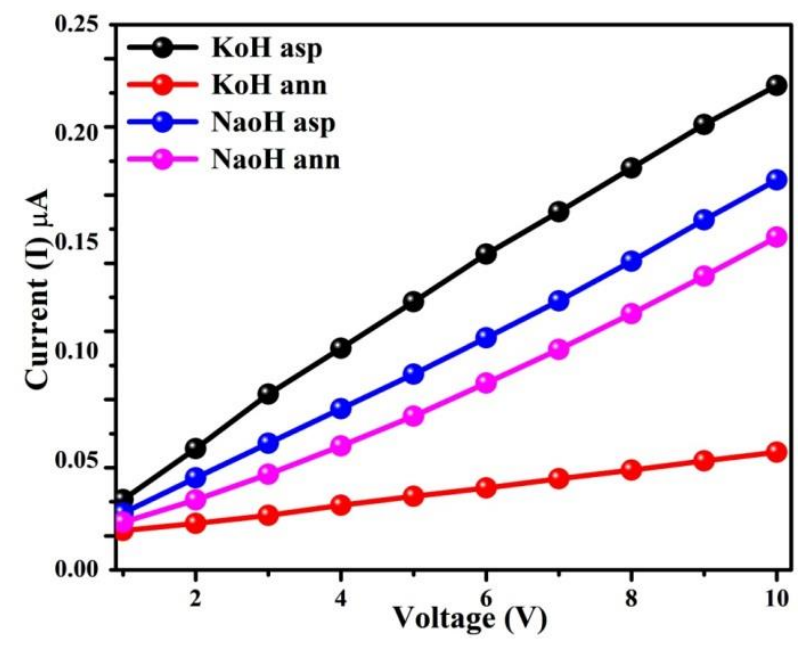

Figure 5 I-V characteristics of Strontium oxide nanoparticles.

\section{Conclusion}

The results observed form the SrO nanoparticles enunciate about the structural, optical and electrical properties modification due to the influence of annealing temperature and precipitant. The structural characterization proved that the Strontia nanoparticles are polycrystalline nature with single phase tetragonal structure having preferred orientation along (202) direction. The samples prepared from $\mathrm{NaOH}$ precipitant indicate superior crystalline behavior than the samples prepared from $\mathrm{KoH}$ precipitant owing to its high catalytic activity during particle formation. UV-ViS analysis reveals the presence of broad absorption peak at $322 \mathrm{~nm}$ supports the surface morphology, which further tends to controls the size and purity of the particle. The samples prepared from $\mathrm{KoH}$ precipitant indicate high electrical conductivity than the samples prepared from $\mathrm{NaOH}$ precipitant owing to low band gap energy.

From the obtained results, it has been concluded that the prepared SrO nanoparticles can be applied in optoelectronic devices due to strange optical behavior, electrochemical devices due to large charge recombination.

\section{References}

[1] X. Wang, J. Song, L. Gao, J. Jin, H. Zheng and Z. Zhang, Optical and Electrochemical Properties of Nanosized NiO via Thermal Decomposition of Nickel Oxalate Nanofibres, Nanotechnology, 16(1) (2005) 37-39.

https://doi.org/10.1088/0957-4484/16/1/009

[2] K.R. Nemade, S.A. Waghuley, UV-VIS spectroscopic study of one pot synthesized strontium oxide quantum dots, Results in Physics 3 (2013) 52-54.

https://doi.org/10.1016/j.rinp.2013.03.001

[3] M. Koberg, M. Cohen, A. Ben-Amotz, A. Gedanken, Bio-diesel production directly from the microalgae biomass of Nannochloropsis by microwave and ultrasound radiation, Bioresource Technology, 102(5) (2011) 4265-4269.

https://doi.org/10.1016/j.biortech.2010.12.004

[4] M. Koberg, R. Abu-Much, A. Gedanken, Optimization of bio-diesel production from soybean and wastes of cooked oil: combining dielectric microwave irradiation and a SrO catalyst, Bioresource Technology, 102 (2011) 1073-1078.

https://doi.org/10.1016/j.biortech.2010.08.055

[5] Sang_won Lee, Enhanced UV stability of perovskite solar cells with a SrO interlayer, Organic Electronics, 63 (2018) 343-348. https://doi.org/10.1016/j.orgel.2018.09.019

[6] Han Wang, Xiaoqiang Jiang, Brian G. Wills, Atomic Layer Deposition of SrO: Substrate and Temperature Effects, MRS Online Proceedings, 1494 (2013) 179-183.

[7] Y. Yang, H. Chen, B. Zhao, and X. BaO, Size control of $\mathrm{ZnO}$ nanoparticles via thermal decomposition of zinc acetate coated on organic additives, Journal of Crystal Growth 263(1-4) (2004) 447-453.

https://doi.org/10.1016/j.jcrysgro.2003.12.010

[8] K. R. Prasad and N. Miura, Electrochemical synthesis and characterization of nanostructured tin oxide for electrochemical redox supercapacitors, Electrochemistry Communications 6(8) (2004) 849-852.

https://doi.org/10.1016/j.elecom.2004.06.009

[9] C.T. Hsieh, H. Teng, Influence of oxygen treatment on electric double-layer capacitance of activated carbon fabrics, Carbon 40(5) (2002) 667-674.

https://doi.org/10.1016/S0008-6223(01)00182-8 
[10] B.M. Mandal, Conducting polymer nanocomposites with extremely low percolation threshold, Bulletin Materials Science 21(2) (1998) 161-165.

[11] M. Kim, S.A. Hong, N. Shin, Y.H. Lee, Y. Shin, Synthesis of strontium titanate nanoparticles using supercritical water, Ceramics International 42(15) (2016) 17853-17857.

https://doi.org/10.1016/j.ceramint.2016.08.120

[12] K.B. Ahmed, T. Raman, A. Veerappan, Jacalin capped platinum nanoparticles confer persistent immunity against multiple Aeromonas infection in zebrafish, Scientific Reports, 8 (2018). https://doi.org/10.1038/s41598-018-20627-3

[13] Taimur Athar, Synthesis and Characterization of Strontium Oxide Nanoparticles via Wet Process, Materials Focus 2(6) (2013) 450-453.

[14] Deepthi S, Amna A, Gafoor AA, Sivashanmugam SVN, Jayakumar R. Journal of Materials Chemistry B.2016;4(23):4092-4103.

[15] E.O. Naor, M. Koberg, A. Gedanken, Nonaqueous synthesis of $\mathrm{SrO}$ nanopowder and $\mathrm{SrO} / \mathrm{SiO}_{2}$ composite and their application for biodiesel production via microwave irradiation, Renewable energy 101 (2017) 493-499. https://doi.org/10.1016/j.renene.2016.09.007
Funding

No funding was received for conducting this study.

\section{Authors Contribution}

Conceptualization, methodology, manuscript preparation, review and editing (RS). Manuscript Review and Editing (TIP, KTV \& MJP). All the authors have read and approved the manuscript.

\section{Data Availability}

The data that support the findings of this study are available from the corresponding author upon reasonable request.

\section{Ethics Approval}

Ethics approval doesn't required for this study

\section{Conflict of interest}

The authors have no conflicts of interest to declare that they are relevant to the content of this article.

\section{About The License}

(c) The author(s) 2020. The text of this article is open access and licensed under a Creative Commons Attribution 4.0 International License 